\title{
Is it all bad? Saudi EFL student perceptions of the role of anxiety when writing
}

\author{
Salah Alfarwan \\ English Department, College of Science and Humanities, Majmaah University, \\ Rumah, Saudi Arabia
}

\begin{abstract}
Purpose - The study aims to ascertain the degree to which Saudi tertiary level writers experience foreign language (FL), English, writing anxiety compared with other variables known to affect writing, such as motivation, types of self-efficacy or teacher assistance, how anxiety relates to those other variables, and whether the effects of anxiety on writing are always perceived as negative.

Design/methodology/approach - This study used questionnaire and interview data following writing tasks in two conditions (practice and exam).

Findings - The key findings were that, regardless of level or writing condition, writing anxiety emerged as the least strongly experienced of all the relevant variables. From factor analysis, it was found to be associated with perceived general English language proficiency and writing strategic ability and not with topic knowledge, teacher or motivational variables. Contrary to the assumption in much of the literature, many participants experienced some anxiety as having a positive effect on their English writing, in certain ways and at certain times (dependent on the writing condition) and not solely a negative impact.

Research limitations/implications - Implications are drawn for theory and for the teaching of writing. Practical implications - Drawn towards the end of the paper.

Social implications - Any research on factors that affect writing seemingly has practical value and implications in such contexts, in addition to interest for L2 writing research and theory.

Originality/value - There remains a question that applies across the whole field of anxiety research in education and applied linguistics concerning whether anxiety is, as often assumed, always bad and so constitutes something to be removed, or whether in fact some degree of anxiety is actually helpful (Alpert and Haber, 1960). This study aims to answer.
\end{abstract}

Keywords L2 writing, EFL, Writing anxiety, Apprehension, Self-efficacy

Paper type Research paper

\section{Introduction}

Learner anxiety while learning and using English as a foreign language (FL) has enjoyed a good deal of attention since the seminal work of Horwitz et al. (1986). Much of it has, however, targeted undifferentiated classroom anxiety, as retrospectively perceived in general terms and regardless of any specific task being performed. Furthermore, Horwitz's widely used instrument in fact largely focused on speaking and neglected other skills. More recently anxiety, also often termed apprehension, has, however, begun to be investigated for separate FL skills, including writing (Aloairdhi, 2019; Latif, 2015). Nevertheless, anxiety remains often considered separately and not within the context of other well-known variables that impact on writing, and that it may be related to, such as interest or self-efficacy (Bandura, 1997). Furthermore, its likely variability depending on the type of writing task being performed has not been fully investigated. Finally, there remains a question that applies across the whole

(C) Salah Alfarwan. Published in Saudi Journal of Language Studies. Published by Emerald Publishing Limited. This article is published under the Creative Commons Attribution (CC BY 4.0) licence. Anyone may reproduce, distribute, translate and create derivative works of this article (for both commercial and non-commercial purposes), subject to full attribution to the original publication and authors. The full terms of this licence may be seen at http://creativecommons.org/licences/by/4.0/legalcode

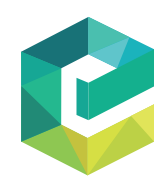


SJLS

2,1

\section{2}

field of anxiety research in education and applied linguistics concerning whether anxiety is, as often assumed, always bad and hence constitutes something to be removed, or whether in fact some degree of anxiety is actually helpful (Alpert and Haber, 1960).

These are the themes that this paper attempts to illuminate using the context of writing in EFL by tertiary level students in Saudi Arabia as an example. In the Saudi context, writing in English at this level is an enduring problem since most majors are delivered through the medium of English but students do not possess the writing ability to write competently, or at any length, in academic English. Therefore, exercises and exams in many subjects have to be limited to forms such as multiple choice and short answer formats that avoid the need for extensive academic writing, which would be encountered at this level in the West. Consequently, any research on factors that affect writing has practical value and implications in such contexts, in addition to interest for L2 writing research and theory.

\section{Literature review}

Due to space limitation, this review is necessarily confined to the above mentioned themes of interest in this study. In essence, it will suggest that a stereotypical view of writing anxiety among learners of English as an FL has emerged which needs to be justified or challenged more than it has been. The account is, therefore, in three sections addressing in turn: the level of anxiety compared with other factors that affect writing, the relationships among those factors and whether all levels of anxiety are in fact universally "bad".

\subsection{Factors affecting writing}

It has long been apparent that the manner of execution and quality of learners' writing in English does not simply depend on their actual English language ability or writing proficiency (Angelova, 1999). A number of other variables have been identified as having varying degrees of influence. First, many researchers, like Huerta et al. (2017), highlight the writer's selfperceived or subjective level of ability (often called self-efficacy), which may not exactly reflect their actual competence as measured by a researcher (objective ability). If a writer does not believe they have the necessary ability, they may not exploit their true potential when writing, regardless of their true/objective ability. Alternatively, they may be over-confident. Writing self-efficacy may be further broken down into more specific beliefs relevant to writing such as self-perceived language knowledge versus background knowledge of topic versus writing strategic competence (Olinghouse et al., 2015; Raoofi et al., 2012).

Aside from the writer's knowledge/skills and beliefs, other studies in instructed contexts focus on the impact of teacher, both in framing and supporting writing as it is performed and notably in feedback provided afterward (Archibald, 2004). Affective writer characteristics such as motivation/interest (Hashemian and Heidari, 2013), and the present concern, anxiety (e.g. Latif, 2015), are also found to be relevant factors.

Studies of writing anxiety are, however, characterized by often being conducted without inclusion of a representative range of other known factors affecting writing, a limitation which the present study aims to avoid. Aloairdhi (2019), for example, illustrates a common practice of investigating factors affecting writing anxiety, but not including factors parallel with anxiety that are seen as affecting writing. Like FL anxiety in general, writing anxiety is also notable for being represented as occurring at high levels, due to FL classes inevitably requiring learners to perform skills in which they lack proficiency (Gardner and MacIntyre, 1993), contrasting with subjects such as history centered on knowledge rather than skills. This has tended to lead to an assumption that FL anxiety needs to be reduced as a matter of course (Alamri, 2020; Gkonou, 2011). In fact, though some studies do report high levels (e.g. for Saudi females in Altukruni, 2019), many FL anxiety studies record only moderate rates 
(e.g. Aloairdhi, 2019; Gkonou, 2011; Piechurska-Kuciel, 2012). The present study also addresses these assumptions.

Furthermore, research usually treats writing anxiety without considering that all writing tasks may not evoke the same level of writing anxiety. Yet, common sense would suggest that certain aspects of writing tasks might alter the anxiety of the writer. One such is the difference between writing for practice and writing for assessment/exam, which the present study will address. Indeed, fear of assessment is one of the main sources to emerge from the work of Horwitz et al. (1986). In a similar way, a person's topic knowledge or self-efficacy and their interest may vary widely between writing tasks, depending on the topic required to write about.

Now, while a specific category of writing apprehension/anxiety is widely recognized, typically it is only measured for non-specific situations. Indeed, Daly and Miller's (1975) instrument and its successors (e.g. used by Aloairdhi, 2019), are worded in that way: e.g. "I am nervous about writing" is surely hard to respond to without specifying some particular writing task condition or topic. By contrast, this study proposes to compare student performance on a low anxiety provoking task (classroom practice writing) with that on a high anxiety provoking task (exam writing).

\subsection{Inter-relationships among factors affecting writing}

In studying skills whose execution is affected by a number of factors, researchers ultimately aim not only to identify the different types of influential factor but also to determine their interrelationship with each other. In short, they propose models of the factors affecting the target process/skill. Therefore, in the present case one may ask how anxiety relates to other variables that explain how writing is done and its success. In the area of FL writing, Flower and Hayes (1981) proposed a well-known model that distinguished between task-related factors (e.g. topic, genre and audience of the writing assignment) and writer-based factors, which they described as residing in long term memory. The latter included knowledge of topics, audiences and writing plans (knowledge of discourse types such as narrative and argumentative). If they had elaborated this for non-native writers, it would no doubt have included further writer attributes such as types of language ability, motivation and anxiety; however, the researchers were more interested in the part of the model analyzing the writing process itself.

The focus of writing models more on the nature of the writing process rather than the factors affecting it, seen also in later models such as that of Bereiter and Scardamalia (1987), means that the interrelations among those factors that affect the process remain obscure. Studies often examine one factor alone, or just a small subset. The most recent proposed model (Lee, 2020) lists eight factors affecting writing including apprehension and self-efficacy, but again does not go far in specifying interrelations among those factors. Hence, although significant effects of anxiety on performance of many kinds of task have been found, the possible relationship of anxiety with a comprehensive range of other factors is not typically considered. Singh and Rajalingam (2012), for example, include only one other. Raoofi et al. (2012) report some studies where anxiety has been examined for its relationship with self-efficacy, but these studies tend to treat self-efficacy as just one indivisible construct, not more realistically as containing several rather different self-perceived competences relevant to writing, whose relationships with anxiety might differ. Nor have such studies demonstrated whether such relationships might depend for example on classroom writing task-related variables such as writing for practice versus for an exam, which this study considers.

\subsection{Negative or positive impact of anxiety}

Anxiety is almost universally assumed only to have a negative effect on performance (Badrasawi et al., 2016; Fischer and Meyers, 2017). Indeed, according to Cornwell and McKay (2000), the writing of highly apprehensive students was found to be shorter, syntactically
The role of anxiety in EFL writing 
SJLS

2,1

4

more restricted, with less use of qualification and generally of poorer quality. Hence, anxiety is widely regarded as something, which needs to be understood only so that teachers can intervene to reduce it (Olivier and Olivier, 2016) or so that students can develop their own strategies to mitigate it (Badrasawi, 2016; Britt et al., 2018).

As mentioned above, however, the actual level of anxiety measured in studies is often only moderate. Furthermore, in the wider literature, apprehension or anxiety has in fact been found in some circumstances to be beneficial (Coplan et al., 2012), especially in sport contexts. For instance, a low rather than zero level of apprehension/anxiety can increase task motivation, preparation and attention (Strack and Esteves, 2015). That would imply a quadratic $\cap$ shaped relationship between anxiety and task performance rather than the linear relationship that is standardly assumed in research on factors affecting language performance: very low and high anxiety would have a bad effect while low-middling anxiety would be beneficial.

Some researchers (from Alpert and Haber, 1960, to Strack and Esteves, 2015) even distinguish two kinds of anxiety, one beneficial, termed facilitative and the other harmful, termed debilitative. Facilitative anxiety is here defined subjectively by what the individual perceives to be its effect (Brown, 2021) and that is how it will be approached in this study. It is the level of anxiety, which is perceived as motivating and associated with some task or problem that is considered a challenge rather than a threat. Students who experience more facilitating anxiety when taking tests have been found to achieve higher average test scores regardless of discipline (Kader, 2016).

In yet other studies, however, apprehension yields no significant relationship either positive or negative with essay scores (Olivier and Olivier, 2016). This variety of findings in the literature immediately presents the possible benefits of writing anxiety as worthy of further research.

\section{Research questions}

The review above has shown some conflict in opinions and findings concerning how strong writing anxiety really is among university students, how it relates to other factors that affect writing quality, and especially, whether all levels of anxiety greater than zero are in fact damaging. In order to contribute to the FL writing research field in understanding of these issues, the following questions will, therefore, be answered, with respect to Saudi English major university students at two levels, writing in two different conditions.

(1) How strongly do students feel they experience writing anxiety compared with other subjective variables that influence writing?

(2) What other subjective variables is anxiety most related to and how?

(3) Is there any evidence of a positive effect of some level of anxiety?

(4) Are any of the above subject to variation depending on the writing task conditions or the student level?

\section{Method}

The data were gathered at a typical Saudi state university before the COVID 19 crisis, so anxiety arising for that reason could not have affected the data.

\subsection{Participants}

Students were approached to participate from two English writing courses. One course was a part of the Intensive English Course (IEC) provided to prepare students for English medium 
study of their majors immediately following. The second course was part of the first year of the English major (EM) undergraduate program. All participants were Saudis speaking Arabic as L1, aged 19-21.

In total, 57 IEC students (22 male, 35 female) and 60 EM students (33 male, 27 female) answered the questionnaire. Sixteen of those agreed to participate in interviews. Those consisted of one participant for each possible combination of the values of four two-valued variables: male-female; IEC-EM; high anxiety-low anxiety (as measured on the questionnaire); exam essay or practice task essay. Participants are identified below by their four values on those variables.

\subsection{Questionnaire}

A questionnaire (which also contained some items designed to gather data for another separate study) was constructed to gather demographic information on the participants and to elicit rating scale response data concerning subjective factors known from the literature to influence writing quality. The latter used statements about how much the student claimed to possess a stated attribute (e.g. topic knowledge), covering nine variables that were prominent in the literature reviewed, including anxiety. They were responded to on a low-high 1 to 5 scale and were worded to be immediately retrospective, related to the writing the respondent had just completed. This was designed with the aim to elicit valid reports about recent writing in a particular condition.

The questionnaire was composed in English, then, translated into Arabic by an expert bilingual translator. It was piloted with ten students from the same population as that sampled for the main study and they confirmed that it was understandable and not complicated.

\subsection{Interviews}

Interviews were conducted in Arabic and again were linked to the writing recently performed for the researcher. Open questions were used with appropriate follow up questions suited to what was said. The aim of these was to elicit rich information about the students' anxiety as they experienced it, in contrast with other factors and its perceived effects. Relevant to this study the questions explored:

(1) how far participants thought anxiety affected their writing

(2) what factors they thought affected their writing in addition to anxiety

(3) whether they thought anxiety had any positive or only negative impact.

\subsection{Procedure}

Two equivalent essay prompts were used to elicit writing in weeks 5 and 7 of the writing courses. Each essay was written by one group as an exam task and by the other as a practice task using a counterbalanced design: about half of the participants wrote on the first topic in the exam condition and on the second in the practice condition, while the other half did the opposite. In this way, it was planned that topic differences would not be confounded with the two conditions.

The topics were selected to be as parallel as possible. Both of them were argumentative, targeting current issues that resonate in Saudi Arabia. One was more male focused and the other more female, but it was anticipated that both would be likely to evoke strong opinions in both sexes and thus motivate all participants to write to a similar extent. They were:

(1) Is it a good thing that women are now allowed to drive in the KSA? Why/Why not? 
SJLS

2,1

(2) Should men all learn how to cook? Why/Why not?

As far as was possible, the writing tasks were introduced as normal parts of the student courses and associated examining. In Saudi universities, it is in any case normal for the exams to be set and marked by the class teachers. Since the aim was to conduct the research in the natural conditions of the context, there was no imposition of the precise features of the practice versus exam writing task conditions. These were left to the class teachers to decide, in accordance with the usual customs in the institution. The differences between conditions then were as follows.

The practice-writing task took place in class rather than as homework: typically, the students are first assigned the topic to write a rough draft as an exercise and the work is then read and commented on, usually by a peer who provides feedback on the content and checks for language mistakes of grammar, punctuation and capitalization. The teacher then makes a round of the class to monitor the students' work, after which the final draft is written. In exam conditions, however, the writing task was undertaken without support, as part either of a "quiz" (which in Saudi Arabia is, in fact, a short exam) or of the midterm exam. In the latter case, it was accompanied by other tasks such as an item on connectors or writing short essays/paragraphs on other topics. Exam writing time available for the research essay was usually 20 minutes.

Each writing task was followed closely by the questionnaire, after which the researcher analyzed students' questionnaire responses to identify relatively extreme anxious and nonanxious students for the interviews with select cases, which were conducted shortly after. A female assistant ( $\mathrm{PhD}$ in TESOL from the UK) was trained by the researcher for the interviews with female students. Interviews were predominantly conducted in Arabic with some code switching and took between 15 and 20 minutes.

\subsection{Data analysis}

The questionnaire data were entered into SPSS 25 for statistical analysis. These data failed to exhibit normality of distribution (Kolmogorov-Smirnov test with Lilliefors correction $p<0.001$ on all items). Therefore, nonparametric tests were used wherever possible (e.g. the ordinal option within the generalized linear model).

The interview data were transcribed and translated into English. It was, then, read multiple times by the researcher and an independent expert using thematic analysis and the constant comparison method (Cohen et al., 2011) to identify the emergent categories in the content, especially with respect to: factors that students mentioned as affecting their writing, including but not limited to anxiety; the perceived effects of anxiety on writing, whether beneficial or not; and the role of writing task condition.

\subsection{Reliability and validity}

The validity of the questionnaire items was primarily supported by their sourcing in the literature as described above. Cronbach's alpha for the questionnaire anxiety items was 0.695 indicating satisfactory internal reliability. The validity of the whole study was further supported by critical review by an independent applied linguistics expert.

\section{Results and interpretation}

The results relevant to RQs 1 to 3 will be considered in turn, incorporating any informative information relative to $\mathrm{RQ} 4$ at each stage.

\section{$5.1 R Q 1$}

How strongly do students feel they experience writing anxiety compared with other subjective variables that influence writing? 
The overall means, for each of the subjective variables that were included to represent the range of factors that commonly affect writing, appear in Table 1 . This shows that, taken together, across genders, levels and task conditions, the students felt that they came to their writing tasks with a relatively high level of teacher support, almost 4 on the 1 to 5 scale. Second came their feeling of motivational orientation-the importance of writing for future purposes. That was followed by one of the self-rated knowledge variables, their perceived prior knowledge of the topic, then the other motivational variable, interest. After that, just above the midpoint of the scale at 3.2, came their self-judged strategic ability to plan and revise, then other language knowledge variables and last anxiety, rated with a mean considerably below the midpoint of the scale (3) at 2.45 .

The standard deviations are also informative. They reflect the spread of ratings around the mean for each variable. The spread for anxiety is greater than that for any other variable, showing that a considerable range of degrees of apprehension was present in the participants. Given that the possible range of an $S D$ for these data are $0-2.01$, it can be seen that the $S D$ (1.161) is more than half of its possible maximum value. This is partly due to the fact that the distribution is bimodal. Regardless of writing condition, the peaks of the distribution were at 1 (very low) and 3 (moderate) on the $1-5$ rating scale. This suggests that the sample contained two distinct kinds of participant, respectively, with low anxiety and moderate anxiety.

These results may be interpreted as showing that the teachers in the context do in fact support the students assiduously when writing, and the students realize that. This is confirmed by personal experience where I have often observed that teachers are keen to make everything easy enough for the students, whose absolute English proficiency level is often low. They show this support through choosing tasks, whether for practise or actual assessment, that are well within the students' capability and/or by providing comprehensive scaffolding for what to do.

The relatively greater reported presence of motivation in the form of a felt future need for English writing compared with interest, shows perhaps that the students are aware of their real life future needs, whether in future study or work, and that this exceeds their interest. Ideally both extrinsic (needs driven) and intrinsic (liking driven) motivation would be high, and in this case both are in fact well above 3 .

Among the knowledge areas, it is not surprising that they report greater knowledge of the topics than of the strategic and linguistic aspects relevant to writing since the task topics were chosen to be well known. It is noticeable however that the lowest rated knowledge areas are the key ones for writing: self-rated writing ability itself and knowledge of writing genres.

\begin{tabular}{llcc}
\hline & & & $\begin{array}{c}\text { Std. } \\
\text { Deviation }\end{array}$ \\
\hline The level of support which the teacher gives before and during English & Instruction & 3.94 & 0.952 \\
$\begin{array}{l}\text { writing tasks } \\
\text { The importance for me in the future of being able to write well in }\end{array}$ & Motivation & 3.82 & 1.106 \\
$\begin{array}{l}\text { English } \\
\text { My level of knowledge of the topic }\end{array}$ & Knowledge & 3.49 & 1.020 \\
$\begin{array}{l}\text { My interest in writing in English } \\
\text { My level of ability to plan and revise what I wrote }\end{array}$ & Motivation & 3.44 & 1.040 \\
$\begin{array}{l}\text { My general English language ability } \\
\text { My general English language writing ability }\end{array}$ & Knowledge & 3.22 & 1.007 \\
$\begin{array}{l}\text { My level of knowledge of the kinds of composition I am expected to } \\
\text { write (e.g. narrative, problem-solution, argumentative, etc.) }\end{array}$ & Knowledge & 3.09 & 0.868 \\
My level of anxiety when I wrote in English & Affect & 3.08 & 1.082 \\
\end{tabular}

The role of anxiety in EFL writing

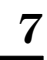


SJLS

2,1

8

This suggests that, on average, they entertain self-efficacy beliefs with respect to writing at a level only just above moderate.

Finally, it is most notable that anxiety is reported as the least present and indeed below the midpoint of the scale $(3=$ moderate). In fact only $16 \%$ of participants reported anxiety above the moderate level. This goes against those studies that give the impression that high anxiety commonly occurs (e.g. Altukruni, 2019). However it is consistent with other studies such as Alamri (2020) that found that although anxiety was reported as present it was not, on average, excessive in the Saudi context.

Turning now to the effect of level and writing condition on the above, the most notable finding is that writing task condition had no significant effect. In other words, the students judged the above variables at similar strengths in relation to both tasks. This prima facie supports studies that focus on writing anxiety in general without attention to task differences (e.g. Aloairdhi, 2019; Latif, 2015). However, it could be explained by the fact that, due to the choice of a naturalistic rather than heavily controlled design, the two task conditions were in fact not extremely different. In particular, both had a time limitation and occurred in a formal setting (university teaching room): the main difference was the amount of support available and the fact that the scores counted for course assessment in the exam condition. Thus they were not as different as, for example, if one composition was done at home and the other at university, since home allows for much greater time to be spent and help to be available from family or even private tutors. Anxiety in that condition then remains to be investigated.

The significant differences in the subjective variables in fact mostly involved level and not gender (contrary to Piechurska-Kuciel, 2012) or writing condition. Not surprisingly, EM students (especially the males) claimed significantly greater language knowledge (Wald chi squared $=10.89, p=0.001$ ) and writing knowledge (Wald chi squared $=6.37, p=0.012$ ) than did IEC students. However, they also claimed significantly less interest in writing (Wald chi $s q .=4.17, p=0.041$ ) (see Table 2).

The qualitative data supported the rank order of variables reported above and in addition confirmed the assumption that they affected perceived writing quality. For example many comments confirmed that teacher assistance was considerable and helped writing:

S: yes, ... the teacher has explained fully what we were supposed to do, clear instruction of what was required. The teacher also was helpful to give hints when it was very necessary ...... (EM M Prac Low)

On the other hand, another student showed that the teacher effect on writing could sometimes be negative. However, this was not a direct writing related effect but mediated through her poor classroom management skills:

Table 2.

Mean strengths of the nine subjective variables by level and task condition

\begin{tabular}{|c|c|c|c|c|}
\hline & & & $\begin{array}{ll}\mathrm{W} \\
\mathrm{col}\end{array}$ & $\begin{array}{l}\text { iting } \\
\text { dition }\end{array}$ \\
\hline & IEC & EM & Exam & Practice \\
\hline $\begin{array}{l}\text { The level of support which the teacher gives before and during English } \\
\text { writing tasks }\end{array}$ & 3.89 & 3.99 & 3.87 & 4.01 \\
\hline The importance for me in the future of being able to write well in English & 3.78 & 3.85 & 3.83 & 3.80 \\
\hline My level of knowledge of the topic & 3.44 & 3.54 & 3.44 & 3.54 \\
\hline My interest in writing in English & 3.57 & 3.33 & 3.39 & 3.50 \\
\hline My level of ability to plan and revise what I wrote & 3.13 & 3.31 & 3.21 & 3.24 \\
\hline My general English language ability & 2.96 & 3.31 & 3.18 & 3.09 \\
\hline My general English language writing ability & 2.96 & 3.22 & 3.10 & 3.08 \\
\hline My level of knowledge of the kinds of composition I am expected to write & 3.11 & 3.04 & 3.02 & 3.14 \\
\hline My level of anxiety when I wrote in English & 2.56 & 2.35 & 2.45 & 2.45 \\
\hline
\end{tabular}


S: Well sometimes we take writing classroom exercises and the students are noisy, asking the teacher a lot and sometimes speaking with each other though not allowed but the teacher does not have a strong presence in the classroom, she is a bit too good-hearted and does not make a good classroom management which resulted in noisiness and clamour. (EM F Exam High)
The role of anxiety in EFL writing

There were also reports of high topic knowledge, with associated language knowledge, again paralleling the quantitative results above:

S: Yes, I had a good knowledge about the topic before and had a good set of vocabulary, structure and ideas that fits the topic I was asked to do. (IEC F Prac Low)

With respect to the effect of writing condition, many respondents supported the lack of difference found in the quantitative analysis.

R: What else < affected your writing $>$ ? Like the settings of the exam and things like that

S: No, everything is perfectly fine (EM F Prac High)

$\mathrm{R}$ : What about time limit for doing the exam?

S: It was not an issue (IEC F Exam High)

However, some did recognize differences, although not just those of time and resources that had been expected

$\mathrm{S}$ : Yes, sometimes the time for the task can be a constraint, and the teacher walking in the classroom watching us and sometimes staring at us checking if any cheating is taking place ....also on several occasions, especially in the final exams, students make noises when they submit their exams and leave the exam auditorium. (EM F Prac Low)

In fact, however, classroom noise was mentioned as a factor in both exam and practice conditions, so helps account for the lack of significant differences between conditions in the quantitative data.

Finally, one supported the view that anxiety would differ if the conditions had been more different:

S. . . . the writing task if it were a homework not in class it would be more comfortable as I would take my time and think at ease while in the class writing I'm limited in time and I have to finish within a certain time that makes me stressed (IEC F Prac High)

\section{$5.2 R Q 2$}

What other subjective variables is anxiety most related to and how?

In order to summarize any discoverable underlying pattern of correlations among the subjective variables, a factor analysis was conducted. Two main factors (accounting for $52.1 \%$ of the variance) were identified based on the criteria of having eigenvalues greater than one and being visually distinct from the rest in the scree plot.

The subjective variables that typically predict writing performance fall into two readily interpretable sets (Table 3). The first contains the variables of language knowledge and related strategic skill that are most relevant for writing, together with anxiety negatively loaded. The second contains the variables of non-language knowledge, such as topic, together with teacher assistance and learner motivation. The variable of knowledge of genre hangs between the two sets, presumably reflecting its ambiguous nature as involving both language structure and non-linguistic content (structure of argument).

This finding therefore suggests that anxiety was not specially linked to teacher assistance, though that might have been expected and was supported by some qualitative comments: 
SJLS

2,1

10

S. . . .. The teacher also was helpful to give hints when it was very necessary for instance when I was hesitant of the word spelling, he gave us a help though very limited but that made me very relaxed. (EM M Prac Low)

Possibly, the correlation of perceived teacher support with anxiety was not evidenced quantitatively because, in this context, the former did not vary much across participants.

Anxiety was also not related to the learner's motivation or self-efficacy in respect of level of non-linguistic knowledge. Rather, it was related to the clearly language-related aspects of the task in hand, where learner self-efficacy is only rated moderate.

Given that writing anxiety emerges as most closely associated with language-related selfefficacy of various types, the question arises whether writing anxiety predicts self-efficacy or the reverse, since both are plausible scenarios. This was tested by further analysis of the variables loaded on factor 1 . A form of regression suited to ordinal data (optimal scaling) was used (Tables 4 and 5).

It can be seen that when writing anxiety is the dependent, it is predicted most notably by the strategic self-efficacy variable of self-perceived planning and revising ability. That effect is stronger, and significant, in the practice writing condition; it fails to quite reach significance

\begin{tabular}{lcr}
\hline & \multicolumn{2}{c}{ Component } \\
& 1 & 2 \\
\hline My general English language ability & 0.712 & \\
My general English language writing ability & 0.736 & \\
My level of knowledge of the topic & 0.632 \\
My level of knowledge of the kinds of composition I am expected to write (e.g. narrative, & 0.459 & 0.461 \\
problem-solution, argumentative, etc.) & 0.688 \\
$\begin{array}{l}\text { My level of ability to plan and revise what I wrote } \\
\text { The level of support which the teacher gives before and during English writing tasks }\end{array}$ & & 0.498 \\
$\begin{array}{l}\text { My interest in writing in English } \\
\text { The importance for me in the future of being able to write well in English }\end{array}$ & 0.802 \\
My level of anxiety when I wrote in English & -0.647 & 0.766 \\
\hline
\end{tabular}

Table 4.

Multiple regression of writing self-efficacy variables on writing anxiety as dependent

\begin{tabular}{lccccccc}
\hline & \multicolumn{3}{c}{ Exam } & \multicolumn{4}{c}{ Practice } \\
& Beta & $F$ & Sig & Beta & $F$ & Sig \\
\hline My general English language ability & -0.092 & 0.11 & 0.894 & -0.077 & 0.09 & 0.760 \\
My general English language writing ability & -0.263 & 2.72 & 0.102 & 0.452 & 1.24 & 0.294 \\
My level of knowledge of the kinds of composition I am & 0.194 & 1.01 & 0.390 & 0.087 & 0.19 & 0.827 \\
expected to write & & & & & & \\
My level of ability to plan and revise what I wrote & -0.220 & 2.62 & 0.077 & -0.818 & 8.50 & $<0.001$ \\
\hline
\end{tabular}

\section{Table 5.}

Multiple regression of writing anxiety and self-efficacy variables on writing self-efficacy as dependent

\begin{tabular}{lrrrrrrr}
\hline & \multicolumn{3}{c}{ Exam } & \multicolumn{4}{c}{ Practice } \\
& Beta & \multicolumn{1}{c}{$F$} & \multicolumn{1}{c}{ Sig } & Beta & \multicolumn{1}{c}{ Sig } \\
\hline My general English language ability & \multicolumn{2}{c}{0.520} & 19.90 & $<0.001$ & 0.625 & 7.06 & $<0.001$ \\
My level of knowledge of the kinds of composition I & 0.152 & 1.49 & 0.230 & 0.129 & 0.79 & 0.457 \\
am expected to write ... & & & & & & \\
My level of ability to plan and revise what I wrote & 0.182 & 2.07 & 0.153 & 0.082 & 0.04 & 0.959 \\
My level of anxiety when I wrote in English & -0.147 & 1.41 & 0.238 & -0.077 & 0.05 & 0.815
\end{tabular}


in the exam condition. Possibly this is because students perceive that there is in any case less time to engage in strategic activity of that sort in the exam condition so it has less effect on their perceived performance. The relationship is negative as would be expected since less belief in their ability is naturally associated with greater anxiety. This finding is consistent with Cornwell and Mackay (2000): "highly apprehensive students have been found to lack organizational strategies and tend to revise and edit less than those with low apprehension" (p119).

The second strongest related variable, though far from significant, is writing self-efficacy in both conditions. This suggests that perceived writing proficiency has less impact on writing anxiety than perceived strategic skill, which has implications for teaching. This result also presents an unexpected feature that is suggestive as perhaps needing further research in future, although in these data, it is not significant. This is the finding that, in the practice condition, writing self-efficacy in fact relates positively rather than negatively with writing anxiety (beta $=0.452$ ). This means that it was students with greater self-perceived writing ability who tended to be more anxious in the practice condition than those with less. One can imagine scenarios, which could lead to this, but they must remain speculative. For example, it could be that in this study's context the relatively more proficient writers, who were not in objective absolute terms highly proficient, were more aware of their errors and deficiencies. For that reason, they could be more anxious than relatively weaker students who were perhaps blissfully unaware of the extent of their deficiency. This would be more prominent in practice conditions because, with less pressure than in exam conditions, there is more time to reflect and indeed the possibility to receive teacher or peer feedback that helps draw attention to errors.

Where writing self-efficacy is the dependent the result is quite straightforward. Far and away, the strongest predictor (positively) is perceived general language proficiency $($ beta $>0.5)$ while anxiety and the other variables are far less strongly associated. The picture is similar regardless of writing condition, although the significances are better in the exam condition.

Overall then, the data suggest that, although the factor 1 variables all correlate with each other in some degree, the key possible causal connections among the subjective variables that are supported are that perceived strategic ability, rather than language or writing ability, affects anxiety (but not the reverse) and that general language ability, but not anxiety, affects writing ability. The impact of general language ability on writing ability is intuitively not unexpected and has been found in other studies (Lee, 2020).

\section{$5.3 R Q 3$}

Is there any evidence of a positive effect of some level of anxiety?

From the quantitative evidence, there was no evidence for a $\cap$ shaped relationship between writing anxiety and writing ability. Rather, there was a moderate negative linear relationship ( $r h o=-0.250, p<0.001$ ). From their questionnaire responses, it seems that students' perception of their writing ability becomes less, the more anxiety they have, in accordance with much of the literature referred to earlier. However, a more nuanced picture emerges if one considers the qualitative responses to interview items about anxiety.

Some students again agreed with much of the literature in categorically supporting the view that even a little anxiety is always more harmful, claiming it increased confusion, mistakes, lack of clarity of the writing and consequently lower marks:

S: I'm sure that if I write with no pressure, I'll write down everything clearer and much better.

R: Let's say you have a little anxiety, what will happen?

S: Yeah I'll write things down but it's going to affect my writing and it will not be good. (IEC M Prac Low)
The role of anxiety in EFL writing 
SJLS

2,1

The negative effects were described by others in terms of confidence, akin to self-efficacy, and simply stopping writing altogether, reminiscent of "writer's block":

S: I was distorted and felt like did not know what to do, my mind looked like stopped (IEC M Exam High)

Notably these effects all refer to the impact of anxiety directly on the writing done while performing a task, or just before it, not to any later effect.

By contrast others pointed to anxiety having a different effect at different points in the time course of a task in progress, in this case changing from negative to positive:

R: Do you think that anxiety stopped you writing as well as you could, or actually helped you write better?

S: At the beginning, yes but later such an anxiety made me start and produce writing.

.... I felt anxious and stressed but then I started thinking and writing better. In other words, it pushed me to brainstorm my ideas and think in depth to get as much as possible. (EM M Prac High)

Here the word "push" might suggest that anxiety affects performance through increasing motivation. Alternatively one may see "push" here as a reflection of the idea of "pushed output" being beneficial, where the push comes from a noticed knowledge gap which leads on to learning whatever fills that gap (the output hypothesis of Swain, 1993).

The idea of anxiety having different effects at different points in time when performing a task is interesting because some recent research, using a so-called "idiodynamic" research method different from ours, has discovered that anxiety itself varies from moment to moment during a task in individuals (Gregersen et al., 2014). Asking people to judge their anxiety for an entire task, as is often done, is therefore expecting them to report some kind of average, not a constant value. However, the finding here is not about temporal variation of anxiety itself but rather of its effects. Students perceive those too as varying over time during a task.

With respect to benefit of anxiety, another student was more aware and had clearly in his own mind made the mental connection between anxiety and benefit more explicitly:

R: Okay. Would you say that being anxious will affect your writing in a positive way or a negative way?

S: I could say both positive and negative

R: How?

$\mathrm{S}$ : It is going to affect me badly when I see a topic that is strange for me and need a text to write.

$\mathrm{R}$ : Ok but how is anxiety going to affect you in a good way?

S: It will alert me to be more aware next time, because I do not want to be anxious again. (IEC M Prac High)

Here anxiety is not presented as being good or bad at different moments but rather that at the same moment. Essentially anxiety is stated as bad for effective current processing but good for prompting self-learning and so performing future tasks better. This then shows that assessing the effect of anxiety is even more complex than might be at first thought. Furthermore, this could again be a sign of the output hypothesis at work. Anxiety is seen as helping the student notice ("alert me to") what they do not know which will in turn lead to them learning something so as to be ready for "next time".

Other students also mentioned both immediate effects on current processing ("think twice") and delayed effects via instigation of learning ("study harder"). In this case, however, 
the student sees both those effects as positive and does not appear to have separated them into two categories on his mind:

R: Do you think actually being a bit more anxious would have helped you write better?

$\mathrm{S}$ : Sometime it is yes, because it encourages me to think more deeply and feel more serious, and make me revise and study harder and also make me think twice about what I'm writing. (EMM Exam Low)

It emerges that students see anxiety as having either negative or positive effects for particular current tasks, while prospectively the effects for later tasks are only beneficial.

It was not clear that student level affected anxiety's positive or negative impact, although in the sample EM students mentioned positive effects a little more than IEC students. However, occasional mentions were made of a task condition effect, such as that any positive effect of anxiety disappeared in exam conditions:

S: . . in general anxiety does not help very much especially in exam settings, I feel confused and may impact my performance in other parts of the task. (EM F Prac Low)

$\mathrm{S}:$.... If the task to be done is very crucial or fatal like a final exam for instance, it really makes me very confused and distorted although usually I prepare well in advance but still has a serious impact ... (EM M Exam Low)

\section{Discussion and conclusion}

When considered in contrast with other factors that affect writing, it emerges that student reported anxiety is in fact mostly not reported at a high level but middling to low as indeed in the majority of previous studies (e.g. Alamri, 2020; Gkonou, 2011). The factor that students experience most prominently is the impact of the teacher, through writing preparation and hints, whether the writing task is practice or exam. The factors that correlate best, but negatively, with anxiety are language-related types of self-efficacy and perceived writing strategic competence (rather than teacher support, cf. Piechurska-Kuciel, 2011). Of those, it is the last that is a significant predictor of anxiety: lack of confidence in planning and revising ability most triggers relatively higher rates of writing anxiety. Finally, contrary to most of the literature, there is evidence that many students see some level of anxiety as helpful to motivate them to work harder on a writing task and to make them aware of their gaps in knowledge to assist their learning for future tasks. The benefits are susceptible to being affected by the writing task conditions; however, in exam conditions, they may be diminished.

There are several implications for teaching writing. One is that teachers should not necessarily make it their primary task simply to remove all anxiety from the teaching situation (cf. Alamri, 2020; Gkonou, 2011). Rather, except in genuine cases of extreme debilitating anxiety, they should help students to become more aware of the good side of anxiety and what benefit can be gained from becoming more aware of their limitations, as a guide to what to focus on when learning.

Second, it seems that it is the strategic dimension of writing ability that is the one that needs improving most, followed by writing ability in general. The value of developing good writing strategies is a central feature of the process writing approach to teaching writing (White and Arndt, 1991), which offers many ways in which teachers can develop student skills in planning and revising their written work.

For writing research and theory, the main implication is that recent models of writing such as Lee (2020) need to consider incorporating more links among the factors/predictors and not only between predictors like anxiety and the dependent variable (writing). They also need to consider if positing a negative relationship between anxiety/apprehension and writing is not an oversimplification of the real situation, which is more complex.
The role of anxiety in EFL writing 
SJLS

2,1

For the future, clearly more work needs to be done on the place of anxiety/apprehension among the interrelated factors affecting writing and the conditions under which positive effects of anxiety arise. Indeed perhaps separate models are required for anxiety and the other factors affecting (a) the process of writing and (b) the learning of writing.

\section{References}

Alamri, W. (2020), A Mixed Methods Investigation of Foreign Language Anxiety and Anxiety-Reducing Strategies in the Saudi Context, $\mathrm{PhD}$, University of Essex, Colchester.

Aloairdhi, N.M. (2019), "Writing anxiety among Saudi female learners at some Saudi universities", English Language Teaching, Vol. 12 No. 9, pp. 55-65.

Alpert, R. and Haber, R.N. (1960), "Anxiety in academic achievement situations", The Journal of Abnormal and Social Psychology, Vol. 61 No. 2, pp. 207-215.

Altukruni, R. (2019), English Writing Anxiety in Saudi Undergraduate Female Students, PhD dissertation, University of Tennessee.

Angelova, M. (1999), An Exploratory Study of Factors Affecting the Process and Product of Writing in English as a Foreign Language, Dissertation: State University of New York at Buffalo, ProQuest Dissertations Publishing, p. 9931461.

Archibald, J. (2004), Writing in a Second Language, Subject Centre for Languages, Linguistics and Area Studies Good Practice Guide, available at: http://www.llas.ac.uk/resources/gpg/2175 (accessed 1 May 2021).

Badrasawi, K.J.I., Zubairi, A. and Idrus, F. (2016), "Exploring the relationship between writing apprehension and writing performance: a qualitative study", International Education Studies, Vol. 9 No. 8, pp. 134-143.

Bandura, A. (1997), Self-efficacy: the Exercise of Control, W. H. Freeman, New York.

Bereiter, C. and Scardamalia, M. (1987), The Psychology of Written Composition, Lawrence Erlbaum, Hillsdale, NJ.

Britt, M., Pribesh, S., Hinton-Johnson, K. and Gupta, A. (2018), "Effect of a mindful breathing intervention on community college students' writing apprehension and writing performance", Community College Journal of Research and Practice, Vol. 42 No. 10, pp. 693-707.

Brown, G. (2021), Difference between Facilitative Anxiety and Debilitative Anxiety, Difference Between Similar Terms and Objects, available at: http://www.differencebetween.net/science/differencebetween-facilitative-anxiety-and-debilitative-anxiety/.

Cohen, L., Manion, L. and Morrison, K. (2011), Research Methods in Education, 7th ed., Routledge, London.

Coplan, J.D., Hodulik, S., Mathew, S.J., Mao, X., Hof, P., Gorman, J.M. and Shungu, D.C. (2012), “The relationship between intelligence and anxiety: an association with subcortical white matter metabolism", Frontiers in Evolutionary Neuroscience, Vol. 3 No. 8, doi: 10.3389/fnevo.2011.00008.

Cornwell, S. and McKay, T. (2000), "Establishing a valid, reliable measure of writing apprehension for Japanese students", Japan Association for Language Teaching Journal, Vol. 22 No. 1, pp. 114-139.

Daly, J.A. and Miller, M.D. (1975), "The empirical development of an instrument to measure writing apprehension”, Research in the Teaching of English, Vol. 9 No. 3, pp. 242-249.

Fischer, L.M. and Meyers, C. (2017), "Determining change in students' writing apprehension scores in a writing intensive course: a pre-test, post-test design", Journal of Agricultural Education, Vol. 58 No. 1, pp. 69-84.

Flower, L. and Hayes, J. (1981), “A cognitive process theory of writing”, College Composition and Communication, Vol. 32 No. 4, pp. 365-387, doi: 10.2307/356600.

Gardner, R.C. and MacIntyre, P.D. (1993), “A student's contributions to second-language learning. Part II: affective variables”, Language Teaching, Vol. 26, pp. 1-11, doi: 10.1017/S0261444800000045. 
Gkonou, C. (2011), “Anxiety over EFL speaking and writing: a view from language classrooms", Studies in Second Language Learning and Teaching, Vol. 1 No. 2, pp. 267-281, doi: 10.14746/ssllt. 2011.1.2.6.

Gregersen, T., Macintyre, P.D. and Meza, M.D. (2014), "The motion of emotion: idiodynamic case studies of learners' foreign language anxiety", The Modern Language Journal, Vol. 98 No. 2, pp. 574-588.

Hashemian, M. and Heidari, A. (2013), “The relationship between L2 learners' motivation/attitude and success in L2 writing", Procedia - Social and Behavioral Sciences, Vol. 70, pp. 476-489.

Horwitz, E.K., Horwitz, M.B. and Cope, J. (1986), "Foreign language classroom anxiety", The Modern Language Journal, Vol. 70 No. 2, pp. 125-132.

Huerta, M., Goodson, P., Beigi, M. and Chlup, D. (2017), "Graduate students as academic writers: writing anxiety, self-efficacy and emotional intelligence”, Higher Education Research and Development, Vol. 36 No. 4, pp. 716-729.

Kader, A. (2016), "Debilitating and facilitating test anxiety and student motivation and achievement in principles of microeconomics", International Review of Economics Education, Vol. 23, doi: 10. 1016/j.iree.2016.07.002.

Latif, A.M. (2015), "Sources of L2 writing apprehension: a study of Egyptian university students", Journal of Research in Reading, Vol. 38 No. 2, pp. 194-212.

Lee, J. (2020), "Effects of linguistic and affective variables on middle school students' writing performance in the context of English as a foreign language: an approach using structural equation modeling", Reading and Writing, Vol. 33, pp. 1235-1262, doi: 10.1007/s11145-01910007-2.

Olinghouse, N.G., Graham, S. and Gillespie, A. (2015), "The relationship of discourse and topic knowledge to fifth graders' writing performance”, Journal of Educational Psychology, Vol. 107 No. 2, pp. 391-406.

Olivier, L. and Olivier, J. (2016), "Exploring writing apprehension amongst Afrikaans-speaking firstyear students", Reading and Writing: Journal of the Reading Association of South Africa, Vol. 7 No. 1 , article 89.

Piechurska-Kuciel, E. (2011), "Perceived teacher support and language anxiety in Polish secondary school EFL learners", Studies in Second Language Learning and Teaching, Vol. 1 No. 1, pp. 83-100, doi: 10.14746/ssllt.2011.1.1.5.

Piechurska-Kuciel, E. (2012), "Gender-dependent language anxiety in Polish communication apprehensives", Studies in Second Language Learning and Teaching, Vol. 2 No. 2, pp. 227-248, doi: 10.14746/ssllt.2012.2.2.6.

Raoofi, S., Tan, B.H. and Chan, S.H. (2012), "Self-efficacy in second/foreign language learning contexts", English Language Teaching, Vol. 5 No. 11, pp. 60-73.

Singh, T.K.R. and Rajalingam, S.K. (2012), "The relationship of writing apprehension level and selfefficacy beliefs on writing proficiency level among pre-university students", English Language Teaching, Vol. 5 No. 7, pp. 42-52.

Strack, J. and Esteves, F. (2015), "Exams? Why worry? Interpreting anxiety as facilitative and stress appraisals", Anxiety Stress Coping, Vol. 28 No. 2, pp. 205-214.

Swain, M. (1993), "The output hypothesis: just speaking and writing aren't enough”, The Canadian Modern Language Review, Vol. 50 No. 1, pp. 158-164.

White, R. and Arndt, V. (1991), Process Writing, Addison-Wesley-Longman, Essex.

\section{Further reading}

Barnes, L.L.B., Harp, D. and Jung, W.S. (2002), "Reliability generalization of scores on the Spielberger state-trait anxiety inventory", Educational and Psychological Measurement, Vol. 62 No. 4, pp. 603-618, doi: 10.1177/0013164402062004005. 
SJLS

2,1

16

\section{About the author}

Salah Alfarwan went to reputable academic schools with excellent research practices like Helsinki University, Exeter University and Leeds University ending up with a $\mathrm{PhD}$ in Applied Linguistics from Essex University in the UK. Currently, he is teaching at Majmaah University in Saudi Arabia. He has over 20 years of experience in teaching and researching in applied linguistics with over 20 publications in internationally reputable journals. His interest centers around reading and writing, course syllabus design and analysis, sociolinguistics, psycholinguistics and basically along with other relevant areas. Salah Alfarwan can be contacted at: s.alfarwan@mu.edu.sa

For instructions on how to order reprints of this article, please visit our website: 